\title{
Determination of dissolved oxygen in seawater by direct spectrophotometry of total iodine
}

\author{
Su-Cheng Pai ${ }^{\mathrm{a}}$, Gwo-Ching Gong ${ }^{\mathrm{a}, \mathrm{b}}$ and Kon-Kee Liu ${ }^{\mathrm{a}, \mathrm{c}}$ \\ "Institute of Oceanography. National Taiwan University. Taipei, Taiwan

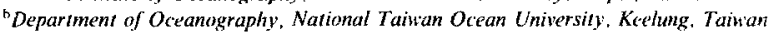 \\ 'Institule of Earth Sciences, Academia Sinica. Taipet. Taiwan \\ (Received 20 January 1992; revision accepted 6 May 1992)
}

\section{ABSTRACT}

Pai, S.-C.. Gong. G.-C. and Liu. K.-K., 1993. Determination of dissolved oxygen in seawater by direct spectrophotometry of total iodine. Mar. Chem., 4i: 343-351.

A modified procedure has been proposed for the colorimetric determination of dissolved oxygen in seawater to improve its precision and accuracy. When a pickled sample is acidified, iodine liberated in the iodometric reaction is measured by direct spectrophotometry at $456 \mathrm{~nm}$. Loss of molecular iodine by volatilization is eliminated by transferring the sample to a flow cuvette without contact with air. The method was calibrated for oxygen by spiking krown amounts of potassium iodate. Precision was found at better than $0.2 \%$ r.s.d. (full scale). Evaluation of accuracy was made by comparison with calculated oxygen solubilities. which shows a relative bias of no more than $0.5 \%$ for oxic waters. The analytical throughput was much faster than that of the standard tifration procedure.

\section{INTRODUCTION}

The Winkler titration method (1888) has been the dominant technique for the determination of dissolved oxygen in seawater for over a century. It is generally based on the reaction of oxygen with $\mathrm{Mn}^{2+}$ in alkaline medium followed by reaction of the $\mathrm{Mn}^{3+}$ or $\mathrm{Mn}^{4+}$ with acidic iodide solution. The resultant iodine is determined titrimetrically with standard thiosulphate. Although intricate modifications have been made to improve considerably the precision of the original method (see e.g. Carpenter, 1965a, b; Green and Carritt, 1966), later including the use of photometric and potentiometric end-point detection devices, the accuracy of the routine

Correspondence to: Dr. S.C. Pai. Institute of Oceanography, National Taiwan University, P.O. Box 23-13, Taipei, Taiwan. Tel: 886-2-362-7358; Fax: 886-2-363-5165. titration process is still much the same as it was two or three decades ago.

Riley (1975), who has sunmarized the resuits of intercalibration work on the Winkler titration methods, has suggested that a very important source for the error is the uncertainty in the standardization of thiosulphate, because of its instability. An accuracy of better than 1\% can be achieved by titration but only under extremely careful conditions. A much simpler non-titrimetric approach, avoiding the use of thiosulphate, had been proposed by several workers. This involves direct measurement of the brown color which is generated when the pickled sample is acidified (Broenkow and Cline, 1969). The color results from a mixture of molecular iodine and triiodide ion. The latter is generated by the complexation reaction of molecular iodine with excess iodide (Burger and Liebhafsky, 1973):

$$
\mathrm{I}_{2}+\mathrm{I}^{-} \leftrightarrow \mathrm{I}_{3}^{-} \quad \mathrm{K}=725
$$


Tri-iodide ion exhibits a strong absorption with a maximum at $350-360 \mathrm{~nm}$. Wong (1982) has estimated the molar extinction coefficient of tri-iodide to be $1.9 \times 10^{4} \mathrm{M}^{-1} \mathrm{~cm}^{-1}$ at $353 \mathrm{~nm}$. The sensitivity is sufficient to cover the oxygen concentration range found in natural samples. However, a review of the literature shows that direct photometry may not be as precise as titrimetric methods (Riley, 1975). For this reason Broenkow and Cline (1969) suggested that it is useful only with low oxygen concentrations. The reason why direct colorimetry is not sufficiently precise at high oxygen concentration is probably due to the unavoidable loss of volatile molecular iodine during the manual transfer of the sample into then colorimeter cell. Green and Carritt (1966) have shown that such loss may be the major source of error in the Winkler procedure. If the exposure of the liquid to air could be controlled, then the colorimetric determination could be made with much better precision and accuracy than that claimed by earlier invesitigators.

A preliminary attempt was made to use a Brinkmann PC-900 optical fiber colorimeter (Brinkmann Instruments, New York, USA) for making the measurement. The optical probe was dipped into the iodine-containing liquid contained in then sample bottle and the absorbance was recorded. Although a precision of ca. $0.6 \%$ (at $420 \mathrm{~nm}$ ) was achieved for replicated measurements, the calibration curve was found to be non-linear compared with results obtained from a parallel Winkler titration. This might be a result of the broad band pass of the light filter in the colorimeter. For this reason, a regular spectrophotometer would be preferable. An attempt to use a flow injection system similar to that suggested by Novic et al. (1988) coupled with a spectrophotometer was unsatisfactory, because the resulting precision was no better than that of the normal titration.

The present study describes a simple fast flow sipper system tied in conjunction with a widebore flow cur ite installed in a double beam spectrophotometer. Measurements of the iodine color appeared much more stable than those with a flow injection system using a narrow bore flow cell. A precision of ca. $0.2 \%$ can be readily achieved. After comparison of hundreds of parallel determinations, the authors are confident that the proposed spectrophotometric method can replace the standard Winkler titration for routine field work.

\section{MATERIALS AND METHODS}

\section{Reagents}

Manganese chloride $\left(\mathrm{MnCl}_{2} \cdot 4 \mathrm{H}_{2} \mathrm{O} 600 \mathrm{gl}^{-1}\right)$, alkaline iodide reagent $(\mathrm{NaOH} 320 \mathrm{~g}$ and $\mathrm{Nal}$ $600 \mathrm{~g}^{-1}$ ) and sulphuric acid (concentrated sulphuric acid $280 \mathrm{mll}^{-1}$ ) were prepared following the suggestion by Carpenter (1965). The concentrations of these reagents werc $3 \mathrm{M}$ for $\mathrm{Mn}^{2+}$;

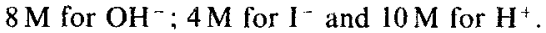

Potassium iodate: prepared by dissolving $1.0665 \mathrm{~g}$ of potassium iodate (dried at $130^{\circ} \mathrm{C}$ ) in 11 of distilled water. Each $\mathrm{ml}$ of this standard contains $5.000 \mu \mathrm{mol}$ of iodate.

Sample bottles: approximately 360 Wheaton BOD bottles (ca. $60 \mathrm{ml}$ capacity, Cat. no. 227494-00, Wheaton, Millville, NJ, USA) were routinely used in this laboratory. All were carefully calibrated and had an average volume of $59.43 \pm 0.34 \mathrm{ml}$ (ca. $0.6 \%$ ). Spectrophotometer: a Shimadzu 160 A double beam spectrometer was fitted with a wide bore quartz flow cell $(10 \mathrm{~mm}$ light path, with an aperture of $11 \mathrm{~mm} \times 4 \mathrm{~mm}$, Cat. no. 176.000-QS, Hellma, Germany) having a total chamber capacity of $450 \mu \mathrm{l}$. A three-way stopcock was fixed outside the spectrophotometer, with connections of Teflon tubing as shown in Fig. 1. The spectrophotometric reading was zeroed against another cuvette when both were filled with distilled water.

Laboratory test samples: distilled water and filtered seawater were prepared in 10 or 251 polyethylene carboys immersed in a large thermostatically controlied water bath. The water was aerated continuously except for a few minutes before samples were withdrawn. 


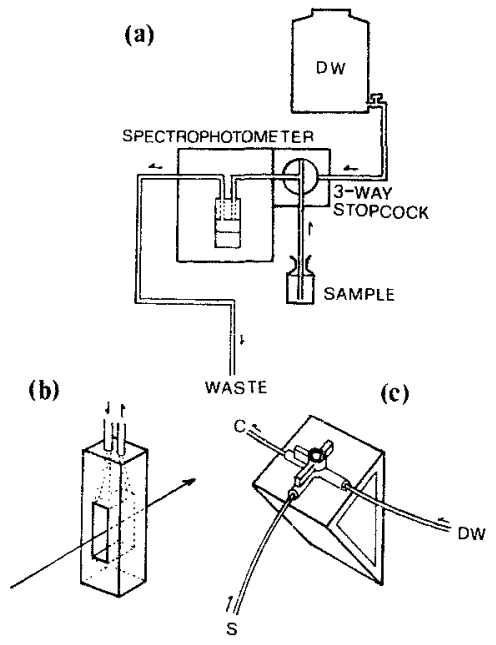

Fig. 1. (a) The sipper/flow cuvette system coupled with a spectrophotometer for the measurement of total iodine. Flow rate was adjustable by changing the diameter or level of the waste tube. (b) The large-bore flow cuvette having a chamber capacity of $450 \mu \mathrm{l}$. (c) The three-way stopcock can be turned to select LOAD. FLUSH, or STOP functions.

\section{Procedure}

A number of $60 \mathrm{ml}$ BOD bottles were flushed and filled with the water samples in the normal way. They were pickled immediately by the addition of $0.5 \mathrm{ml}$ of manganese chloride and $0.5 \mathrm{ml}$ of alkaline iodide reagents by means of dispensers. After being allowed to stand for at least $1 \mathrm{~h}$, the bottle was opened and $0.5 \mathrm{ml}$ of sulphuric acid was added. The bottle was left open and the mixture was gently stirred with a magnetic stirring bar until all the precipitate had dissolved. The solution was then withdrawn into the spectrophotometer by means of the nonpowered sipping flow system (Fig. 1). The end of the inlet tube was placed near the bottom of the bottle to avoid influence from the exposed surface layer. A flow rate of ca. $20 \mathrm{mi} \mathrm{min}$ mas $^{-1}$ wat found to be sufficiently fast to allow the photometric reading to reach a steady state within $20 \mathrm{~s}$. After the absorbance had been recorded the cuvette was flushed with distilled water by turning the three-way valve.

Calibration of the procedure was carried out by adding potassium iodate standard solution to a series of replicate samples. After acidification the bottles were added with $0,1,2$, and $3 \mathrm{ml}$ of $5 \mathrm{mM} \mathrm{KIO}_{3}$ and the absorbances were then measured. Since the addition of iodate changes the total volume, the absorbance readings were normalized by a dilution factor before the calibration was constructed. An empirical extinction coefficient $k$ was evaluated from the slope of the curve. Alternatively, the calibration could be made using a series of reagent blanks, prepared by putting $60 \mathrm{ml}$ aliquot of distilled water or seawater in the bottle and mixed in sequence with sulphuric acid, alkaline iodide and manganese reagents. They were spiked with known amounts of iodate. Details of the calculation are given in the following section.

\section{RESULTS AND DISCUSSION}

\section{Volatilization of iodine}

Loss of iodine vapour is a major source of error in the colorimetric determination of oxygen if the sample is transferred manually to a colorimeter cuvette. Although Knapp et al. (1991) suggested such loss might not be important for titration, we have found that each transfer step could cause $1-3 \%$ decrease on the absorbance reading. The following experiment was carried out to evaluate the magnitude of the volatilization loss when the sample is in a colorimetric cuvette. A sample solution was put into an ordinary $10 \mathrm{~mm}$ cuvette (capacity $4 \mathrm{ml}$ ), and covered by a Tefion cap. leaving no air gap between the liquid and the cap. Under these conditions the absorbance was stable for hours. However, when the cap was removed loss of iodine occurred immediately at a rate which was strongly dependent on temperature and salinity (Fig. 2). The absorbance for a seawater sample was found to decrease at a rate of $-0.030 \mathrm{~A} \mathrm{~h}^{-1}$ $\left(-6 \% \mathrm{~h}^{-1}\right)$ at $22.5^{\circ} \mathrm{C}$, and could reach as high as 


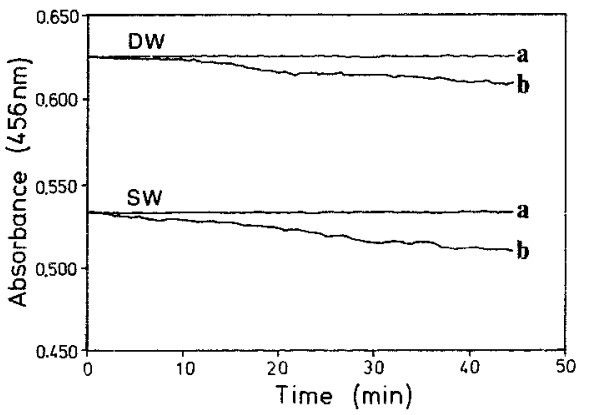

Fig. 2. Vararization of iodine demonstrated by placing the acidified sfimple ints a standard $1 \mathrm{~cm}$ cuvette (capacity $4 \mathrm{ml}$ ), and monitoring the variation of absorbance at $456 \mathrm{~nm}$. Airsaturated distilled water and seawater were pickled at $18.5^{\circ} \mathrm{C}$. The temperature in the cuvette chamber of the spectrophotometer was $22.5^{\circ} \mathrm{C}$. a, covered by Teflon cap; $b$, without cover.

$-0.150 \mathrm{~A} \mathrm{~h}^{-1}$ (ca. $\left.-25--30 \% \mathrm{~h}^{-1}\right)$ at temperature above $30^{\circ} \mathrm{C}$. The rate of volatilization for freshwater was approximately halved. However, the loss rate was almost negligible (less than $-0.2 \% h^{-1}$ ) when the sample was contained in a $60 \mathrm{ml}$ bottle (with free surface of $\sim 2.5 \mathrm{~cm}^{2}$ ) as long as the liquid was not poured out. Thus the bottle containing the acidified sample can be left open for several minutes without detectable loss.

To avoid loss on transfer of the acidified sample to the cuvette the sipper system (Fig. 1) was designed. With this the sample is withdrawn from the lower part of the bottle. Any possible loss of iodine at the surface would not affect the concentration in the bottom layer. If the sipping was stopped, the absorbance reading for the trapped sample could be maintained unchanged for over $1 \mathrm{~h}$. A wide bore cuvette was preferable to one of narrow bore, as the reading is more stable. In addition it can be adapted to a variety of spectrophotometers. In order to reduce the tailing effect arising from the large chamber capacity $(450 \mu \mathrm{l})$, a high flow rate of ca. 15$25 \mathrm{mlmin}^{-1}$ was applied. The absorbance then reached a steady state within $\sim 20$ s and returned to zero in the same time when flushing with

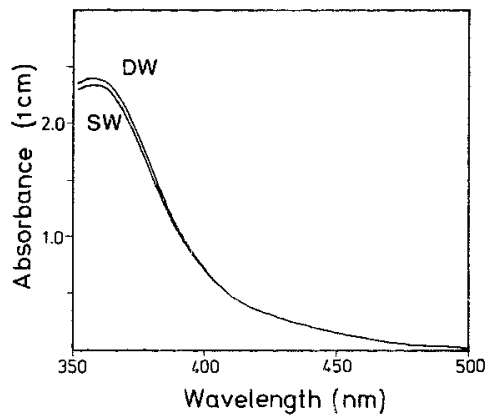

Fig. 3. Absorption spectra of the brownish iodine color in freshwater and seawater media. Aliquot of $0.05 \mathrm{ml}$ of $50 \mathrm{mM}$ iodate was added to $61.5 \mathrm{ml}$ sample (added previously with $0.5 \mathrm{ml}$ of acid, and then $1 \mathrm{ml}$ of the pickling reagents). The final concentrations of iodide and total iodine in both media were ca. $32.5 \mathrm{mM}$ and $122 \mu \mathrm{M}$, respectively.

distilled water. A further advantage of using the non-powered sipper system is that it eliminates the pulsations in flow which are usually associated with a peristaltic pump.

\section{Choice of wavelength}

Although the wavelength of the maximum absorption of the tri-iodide is at ca. $353-356 \mathrm{~nm}$ (Fig. 3). a wavelength of $456 \mathrm{~nm}$ (near the maximum absorption for molecular iodine) was chosen for the following reasons: (1) The sensitivity at $353 \mathrm{~nm}$ is too great to cover the normal range of oxygen concentrations in oxic waters. The measurement at the shoulder of the peak is less sensitive yet it provides enough resolution for oceanographic use. (2) Dissolved organic matter !nsually shows high absorption in the UV and near-UV ranges. There is negligible absorption at $456 \mathrm{~nm}$ and the interference is not as severe as at the lower wavelength. (3) The molar absorptivities of molecular iodine and the triiodide ion are similar at $450-460 \mathrm{~nm}$. The extinction coefficients for the mixture are identical in both freshwater and seawater. (4) In practice, absorbances measured at $456 \mathrm{~nm}$ provide a quick estimate of the oxygen concentration, thus, a 
reading of $0.5 \mathrm{~A}$ in $10 \mathrm{~mm}$ cuvette corresponds with an oxygen concentration of ca. $5.2 \mathrm{mll}^{-1}$. A resolution of $0.001 \mathrm{~A}$ corresponds to an oxygen concentration of ca. $0.01 \mathrm{mll}^{-1}$.

\section{Quantification}

In the Winkler technique, each mole of molecular oxygen in sample will produce two moles of molecular iodine after acidification. Most of this will further complex with excess ioside to from tri-iodide ions. In the procedure described, the final concentration of excess iodide is ca. $0.0167 \mathrm{M}$. Under these conditions $\sim 96 \%$ of the total iodine would be tri-iodiae and $\sim 4 \%$ would be molecular iodine. Other species of iodine such as $\mathrm{IO}^{-}$and $\mathrm{HIO}$ will be negligible under acidic condition. In evaluating the absorbance at $456 \mathrm{~nm}$ the contributions from the tri-iodide ion as well as the free iodine must be taken into account.

When doing the calibration, standard potassium iodate was added to the sample. Each mole of iodate added would produce three moles of additional total iodine.

$$
\mathrm{IO}_{3}^{-}+5 \mathrm{I}^{-}+6 \mathrm{H}^{+} \leftrightarrow 3 \mathrm{I}_{2}+3 \mathrm{H}_{2} \mathrm{O}
$$

It should be noted that the capacities of the BOD bottles will vary. If a bottol of volume $V_{b}$ is filled with a sample having dissolved oxygen concentration of $\left[\mathrm{O}_{2}\right]$ and treated with the pickling reagents (volume $V_{\mathrm{r}}$ ), and sulphuric acid (volume $\left.V_{\mathrm{c}}\right)$, the concentration of total iodine $\left(C_{\mathrm{i}}\right)$ in the solution will be:

$$
C_{\mathrm{i}}=2 \times\left[\mathrm{O}_{2}\right] \times\left(V_{\mathrm{b}}-V_{\mathrm{r}}\right) /\left(V_{\mathrm{b}}+V_{\mathrm{c}}\right)
$$

which will produce an absorbance reading of: $\mathrm{Abs}=k \times b \times C_{\mathrm{i}}$, where $k$ is the empirical extinction ceofficient, and $b$ is the cuvette length Since the value of $\left(V_{\mathrm{b}}-V_{\mathrm{r}}\right) /\left(V_{\mathrm{b}}+V_{\mathrm{c}}\right)$ is almost constant with bottles having capacities ranging from $58-62 \mathrm{ml}$, the initial concentration $C_{\mathrm{i}}$ in all bottles was assumed identical (with an error no more than $0.02 \%)$. If this sample was spiked with an aliquot $\left(V_{\mathrm{a}}\right)$ of potassium iodate (concentra-

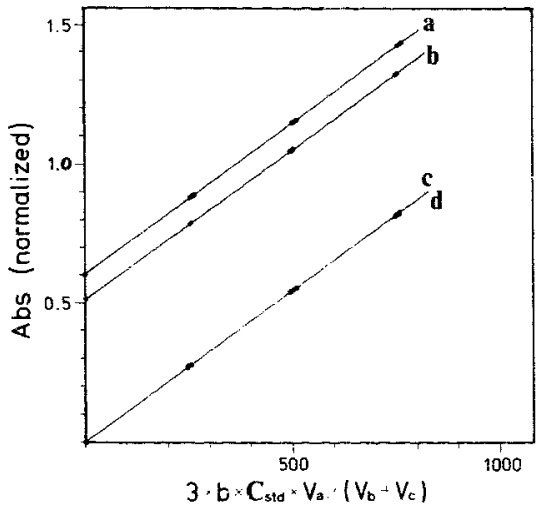

Fig. 4. Typical calibration curves for evaluating the empirical coefficient $k$. Triplicate spikings were made to: a. a pickled distilled water sample; $b$, a pickled seawater sample; c. a distilled water reagent blank: d. a seawater reagent blank. The slopes ( $k$ values) of the four sets of curve were $1084,1086,1087.1084 \mathrm{M}^{\prime} \mathrm{cm}$ ', respectively.

tion $C_{\text {std }}$, the absorbance could be derived as:

$$
\begin{aligned}
& \text { Abs(spiked) }=k \times b \\
& \quad \times \frac{C_{\mathrm{i}} \times\left(V_{\mathrm{b}}+V_{\mathrm{c}}\right)+3 \times C_{\mathrm{scc}}}{V_{\mathrm{h}}+V_{\mathrm{c}}+V_{\mathrm{a}}}
\end{aligned}
$$

It is convenient to normalize the spiked absorbance by a factor to compensate for the dilution effect.

$$
\begin{aligned}
& \text { Abs(normalized) }=\text { Abs(spiked) } \\
& \quad \times\left(V_{\mathrm{b}}+V_{\mathrm{c}}+V_{\mathrm{a}}\right) /\left(V_{\mathrm{b}}+V_{\mathrm{c}}\right) \\
& =\text { Abs(initial) }+k \times b \times 3 \times C_{\mathrm{ctd}} \\
& \quad \times V_{\mathrm{a}} /\left(V_{\mathrm{b}}+V_{\mathrm{c}}\right)
\end{aligned}
$$

Thus the empirical coefficient $k$ can then be obtained from the slope by linear regression of a series of normalized absorbances plotted against increments of total iodine concentration.

Typical calibration curves are shown in Fig. 4. Aliquots of standard iodate solution were added to (a) a pickled distilled water, (b) a pickled seawater, (c) a distilled water reagent blank: and (d) a seawater reagent blank. (The reagent blanks were prepared by adding the pickling reagerits to 
a sample in the reverse order.) The $k$ values calculated from the four sets of data are: 1084 , 1086, 1087 and $1084 \mathrm{M}^{-1} \mathrm{~cm}^{-1}$, respectively, showing that there was no salt effect on the absorptivity. The empirical $k$ value could change from one batch of reagent to another because the concentration of iodide ( $4 \mathrm{M}$ ) in reagent might not be exactly the same.

\section{Turbidity blank}

For waters containing suspended particles, a turbidity blank was obtained by treating the sample with excess thiosulphate or by adding a few drops of sodium sulphite, and then measuring the absorbance again (Riley, 1975). In our experience the turbidity blank of open ocean water rarely exceeds $0.001 \mathrm{~A}$.

\section{Reagent blanks}

At least two possible sources of error can be induced by the addition of reagents: the impurities and the oxygen contained in the pickling reagents. The effect of the former is termed as reagent blank' in this work, which is caused by the small amount of iodine or iodate in the $\mathrm{k}$ reagent as well as other interfering compcunds. It was measured by a procedure similar to that described by Broenkow ano Cline (1969): to : BOD bottle fillted with $60 \mathrm{ml}$ of disillted water were added consecutively $0.5 \mathrm{ml}$ of sulphuric acid. $0.5 \mathrm{ml}$ of alkaline iodide reagent (mixed thoroughly) and $0.5 \mathrm{ml}$ of manganese reagent. The absorbance measured at $456 \mathrm{~nm}$ was accounted for the reagent blank', which should be deducted from the raw absorbance.

The oxygen contained in the pickling reagents was found somewhat difficult to measure. The most practical way to compensate such effect is to subtract an empirical value from the final concentration, as described in eqn. (7).

\section{Calculation}

The absorbance or Abs(raw) found for a sample is corrected by:

$$
\begin{aligned}
\operatorname{Abs}(\text { corr })= & \text { Abs(raw) }- \text { Abs(turb) } \\
& - \text { Abs(rea) }
\end{aligned}
$$

Where $\mathrm{Abs}$ (turb) and Abs(rea) are readings for turbidity and reagent blanks. The oxygen concentration of a sample is then calculated by the following equation:

$$
\begin{aligned}
{\left[\mathrm{O}_{2}\right](\mu \mathrm{M})=} & \text { Abs (corr) } \times \frac{1}{2 \times k \times b} \\
& \times \frac{V_{\mathrm{b}}+V_{\mathrm{c}}}{V_{\mathrm{b}}-V_{\mathrm{r}}}-0.5(\mu \mathrm{M})
\end{aligned}
$$

where $k$ is the empirical extinction coefficient at $456 \mathrm{~nm}$ for the mixture of molecular iodine and tri-iodide; $V_{\mathrm{b}}$ is the volume $(\mathrm{ml})$ of the bottle, $58-61$ in this study; $V_{\mathrm{r}}$ is the total volume $(\mathrm{ml})$ of pickling reagents $(0.5+0.5 \mathrm{ml}) ; V_{\mathrm{c}}$ is the volume (ml) of sulphuric acid $(0.5 \mathrm{ml})$. The final correction term: $-0.5 \mu \mathrm{M}$ (or $-0.01 \mathrm{mll}^{-1}$ ) was added to compensate for the oxygen contained in the pickling reagents. This value was adopted from the estimation by Murray et al. (1968).

Since $\left(V_{\mathrm{b}}+V_{\mathrm{c}}\right) /\left(V_{\mathrm{h}}-V_{\mathrm{r}}\right)$ is nearly a constant $(1.0258 \pm 0.0002)$, and $k, b$ are fixed values, a simplified equation was used in quick calculations:

$\left[\mathrm{O}_{2}\right](\mu \mathrm{M})=F \times \mathrm{Abs}(\operatorname{cor} r)-0.5 \mu \mathrm{M}$

or

$\left[\mathrm{O}_{2}\right]\left(\mathrm{mll}^{-1}\right)=F \times \mathrm{Abs}(\mathrm{corr})-0.01 \mathrm{ml}$

where $F$ is a calibration factor, equivalents to $\left(V_{\mathrm{h}}+V_{\mathrm{c}}\right) /(2 \times k \times b) /\left(V_{\mathrm{b}}-V_{\mathrm{r}}\right) . F$ value may change slightly for different batches of alkaline iodide reagent. usually around $473 \mu \mathrm{M}$ (or $10.59 \mathrm{ml} \mathrm{t}^{-1}$ ) for $1 \mathrm{~cm}$ cuvette depending on the final concentration of iodide present.

\section{Precision and accuracy}

The precision of the present method is demonstrated in Table 1 . For an air-saturated distilled water pickled at $23^{\circ} \mathrm{C}$, the average absorbance was $0.568 \pm 0.0005(n=10)$. For a seawater 
TABLE I

Laboratory evaluation of the precision of the spectrophotometric method

\begin{tabular}{|c|c|c|c|c|c|}
\hline & \multirow{2}{*}{$\begin{array}{l}\text { Retigent } \\
\text { blank } \\
\text { Abs(rea) }\end{array}$} & \multicolumn{2}{|c|}{$\begin{array}{l}\text { Distilled water } \\
\text { pickled at } 23^{\circ} \mathrm{C}\end{array}$} & \multicolumn{2}{|c|}{$\begin{array}{l}\text { Seawater }(34.653 \text { psu }) \\
\text { pickled at } 23^{\circ} \mathrm{C}\end{array}$} \\
\hline & & $A b s($ raw $)$ & Abs(turb) & Ahstraw') & Abstturb) \\
\hline 1 & 0.001 & 0.568 & 0.000 & $0 .+66$ & 0.041 \\
\hline 2 & 0.001 & 0.569 & 0.000 & 0.466 & $0,(60)$ \\
\hline 3 & 0.001 & 0.568 & 0.000 & 0.465 & 0.000 \\
\hline 4 & 0.001 & 0.568 & 0.000 & 0.466 & 0.000 \\
\hline 5 & 0.001 & 0.567 & 0.001 & 0.467 & 0.000 \\
\hline i & $0.00 \mathrm{I}$ & 0.568 & 0.000 & 0.466 & 0.001 \\
\hline 7 & 0.001 & 0.568 & 0.000 & 0.465 & 0.000 \\
\hline 8 & 0.001 & 0.568 & 0.000 & 0.466 & $0.000 \%$ \\
\hline 9 & 0.001 & 0.567 & 0.000 & 0.466 & 0.001 \\
\hline 10 & 0.001 & 0.568 & 0.000 & 0.466 & 0.001 \\
\hline Mean & 0.0010 & 0.5679 & 0.0001 & 0.4659 & 0.0104 \\
\hline $\mathrm{SD}$ & 0.0000 & 0.0005 & 0.0003 & 0.0005 & 0.0005 \\
\hline $\operatorname{RSD}(\%)$ & & 0.09 & & 0.12 & \\
\hline
\end{tabular}

Absorbances were measured at $456 \mathrm{~nm}$ in a $1 \mathrm{~cm}$ flow cuvette.

pickled at the same temperature, the mean result was $0.466 \pm 0.0005(n=10)$. Both show a relative standard deviation about $0.1 \%$. In considering the minimum resolution of the spectrophotometer $(0.001 \mathrm{~A})$, a precision of better than $0.2 \%$ should be reported. The reagent blank wats $0.001 \mathrm{~A}(n=10)$. The turbidity blank for the water test was almost zero. A similar set of measurements was carried out on board a research vessel for at least 50 samples of different depths, each replicated six times. An average relative standard deviation of less than $0.12 \%$ has been consistently obtained over an oxygen concentration of $2.5-4.8 \mathrm{mll}^{-1}$.

The accuracy of the procedure was evaluated by comparing the results with the oxygen solubility taken from the UNESCO tables (Fig. 5). Although it was difficult to verity the exact oxygen concentration for the sample tested, the difference between the measured results and the calculated values was within $0.5 \%$ over a range of 3-6 $\mathrm{ml}^{-1}$. For oxic waters, a relative bias of less than $0.5 \%$ could be radily achieved. Detection limit was estimated by taking 4.65 times the standard deviation of the reagent blank, to be less than $0.5 \mu \mathrm{M}$ or $0.01 \mathrm{mll}^{-1}$.

\section{Comparison with itirution inethod}

A number of parallel determination was carried out on board R/V "Ocean Researcher I" using both spectrophotometric and titrimetric methods. The results are plotted in Fig. 6. Good agreements between the two methods have been found.

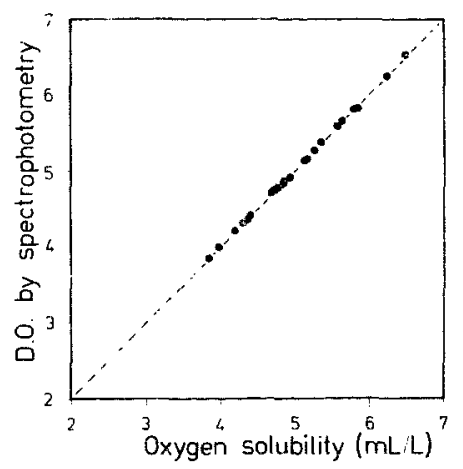

Fig. 5. Comparison on the results for a number of airsaturated samples using the proposed procedure and calculated oxygen solubilities. Test range for temperature: $20-$ $37^{\circ} \mathrm{C}$, for salinity: $0,17.3$ and 34.6 psts. 


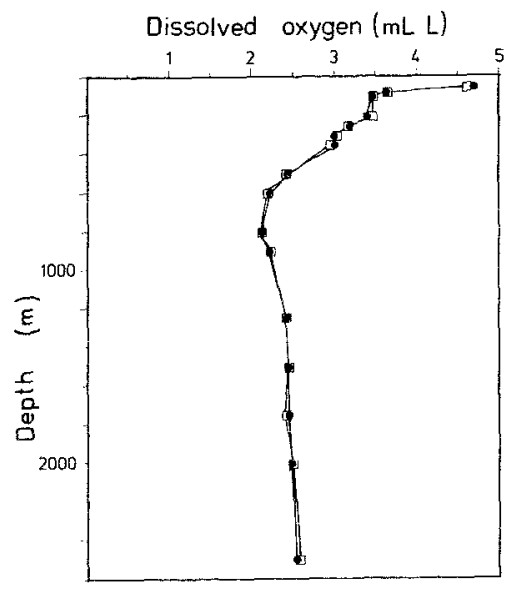

Fig. 6. Comparison of oxygen profiles obtained by (D) Winkler titration and (e) direct spectrophotometry. Both measurements were carried out on board R/V "Ocean Researcher I". Cruise ORI-246, at Station 1090 in the South China Sea on 18 July 1990.

The proposed spectrophotometric method has the following advantages over traditional Winkler titration method: (1) The Winkler titration measures the amount of total iodine in the bottle. The precision and accuracy of the determin tion are very dependent upon the precision . i accuracy of volumetric measurements, i.e. bottle volume, burette volume, and the decision of the end-point for the titre. The spectrophotometric method measures the concentration of total iodine without titration, and therefore those volumetric errors do not exist. (2) The quantification of oxygen in Winkler titration is based on the concentration of thiosulphate. which needs to be standardized by potassium iodate. The spectrophotometric method is more straightforward because it uses potassium iodate directly for calibration, and therefore is more accurate. (3) The preparation work for titration is comparatively tedious and time consuming. The titration throughput is slow even aided by computerized end-point detection devices. The calculation of oxygen concentration requires a note to be made of the volume of each individual sample bottle. In contrast, the spectrophotometric method is much simpler, quicker, and easier to learn. The results are calculated using a simple equation, and there is no need to know the exact volume of each sample bottle. (4) The resolution of the titration method depends on the sample volume used (normally $120-140 \mathrm{ml}$ ). The proposed spectrophotometric method measures the concentration of iodine, therefore smaller bottles $(60 \mathrm{ml}$ or even less) can be used without losing sensitivity.

However, since the final concentration of iodide can slightly affect the accuracy of the spectrophotometric method, and the alkaline iodide reagent is difficult to prepare at required precision owing to its high viscosity, several precautions should be taken: (1) the alkaline iodide reagent may undergo oxidation; this causes a high background value. The reagent blank should be measured frequently. The empirical extinction coefficient $k$ (or factor $F$ ) for different batches of alkaline iodide reagent should be carefully calculated by the iodate spiking experiment jusi before the determination, or whenever the reagent bottle is refilled. (2) The addition of alkaline iodide solution must be performed carefully to ensure that the volume $(0.5 \mathrm{ml})$ is added to all samples with a precision of less than $\pm 5 \%$. Frequent checks on the tip of the dispenser to avoid bubbles is necessary.

\section{CONCLUSION}

Iodometry is still the most precise way of determining dissolved oxygen in seawater. Improvements have been made to the colorimetric determination of liberated iodines by use of an air-contact-free sipper system in conjunction with a wide bore flow cuvette coupled with a regular spectrophotometer. These modifications stabilized the absorbance readings by completeíy eliminating iodine loss and manual movement of the cuvette alignment. They enable a precision of ca. $0.2 \%$ (full scale) to be easily attained even by an inexperienced analyst. The 
spectrophotometric method is very convenient for on-board operation. Its quick throughput is of great value in the calibration of the CTD oxygen sensor. The proposed procedure has been named the 'Shibala' method in our laboratory after a local dice game which shows concsecutive numbers of $4,5,6$ in a row.

\section{ACKNOWLEDGEMENTS}

The authors would like to thank Ting-Yu Kuo, Yih-Chung Li, Chung-Cheng Yang, KwungLung Jeng, Wen-Jong Yang, the Captain and crew of the $R / V$ "Ocean Researcher I" for their kind assistance with the ship-board experiments. The authors are also grateful to Prof. J.P. Riley for his criticism and suggestions on the manuscript. This project was supported by the National Science Council, Taiwan (\# NSC 80-0209. M002a-20).

\section{REFERENCES}

Broenkow, W.W. and Cline, J.D., 1969. Colorimetric determination of dissolved oxygen at low concentrations. Limnol. Oceanogr., 14(3): 450-454.
Burger. J.D. and Liebhafsky, H.A., 1973. Thermodynamic data for aqueous iodine solutions at various temperatures, An exercise in analytical chemistry, Anal. Chem. 45: 600-602.

Carpenter, J.H.. 1965a. The accuracy of the Winkler method for dissolved oxygen analysis, Limnol. Oceanogr.. 10(1): 135-140.

Carpenter, J.H., 1965b. The Chesapeake Bay Institute technique for the Winkler dissolved oxygen method. Limnol. Oceanogr. 10(1): 141-143.

Green, E.J. and Carritt, D.E., 1966. An improved iodine determination flask for whole-bottle titrations. Analyst, 91: 207-208.

Knapp, G.P., Stalcup. M.C. and Stanley. R.J., 1991. lodine losses during Winkler titrations. Deep-Sea Res. 38(1): 121-128.

Murray, C.M.. Riley, J.P. and Wilson. T.R.S.. 1968. The solubility of oxygen in Winkler reagents used for the determination of dissolved oxygen. Deep-Sea Res., 15: 237-238.

Novic. M.. Pihlar, B. and Dular, M.. 1988. Use of flow injection analysis based on iodometry for automation of dissolved oxygen (Winkler method) and chemical oxygen demand (dichromate method) determinations. Fresenius Z. Anal. Chem., 332: 750-755.

Riley, J.P.. 1975. In: Analytical Chemistry of Seawater. Chemical Oceanography, Vol. 3. Academic Press. London. $258 \mathrm{pp}$.

Wong. G.T.F., 1982. The stability of molecular iodine in seawater, Mar. Chem., 11:91-95. 